\title{
Article
}

\section{Self-Assembly Fabrication of Hollow Mesoporous Silica@Co-Al Layered Double Hydroxide@Graphene and Application in Toxic Effluents Elimination}

Jiang, Shu-Dong, Song, Lei, Zeng, Wen-Ru, Huang, Zheng-Qi, Zhan, Jing, Stec, Anna A, Hull, T Richard, Hu, Yuan and Hu, Wei-Zhao

Available at https://clok.uclan.ac.uk/18483/

Jiang, Shu-Dong, Song, Lei, Zeng, Wen-Ru, Huang, Zheng-Qi, Zhan, Jing, Stec, Anna A orcid iconORCID: 0000-0002-6861-0468, Hull, T Richard orcid iconORCID: 0000-0002-7970-4208, Hu, Yuan and Hu, Wei-Zhao (2015) SelfAssembly Fabrication of Hollow Mesoporous Silica@Co-Al Layered Double Hydroxide@Graphene and Application in Toxic Effluents Elimination. ACS Applied Materials \& Interfaces, 7 (16). pp. 8506-8514. ISSN 1944-8244

It is advisable to refer to the publisher's version if you intend to cite from the work. http://dx.doi.org/10.1021/acsami.5b00176

For more information about UCLan's research in this area go to http://www.uclan.ac.uk/researchgroups/ and search for <name of research Group>.

For information about Research generally at UCLan please go to http://www.uclan.ac.uk/research/

All outputs in CLoK are protected by Intellectual Property Rights law, including Copyright law. Copyright, IPR and Moral Rights for the works on this site are retained by the individual authors and/or other copyright owners. Terms and conditions for use of this material are defined in the policies page. 


\section{Activation of carbon dioxide and carbon disulfide by a scandium $\mathrm{N}$-heterocyclic carbene complex +}

Cite this: Dalton Trans., 2014, 43, 34

Received 3rd October 2013, Accepted 11th October 2013

DOI: $10.1039 / c 3 d t 52762 j$

www.rsc.org/dalton

\author{
Polly L. Arnold, *a Isobel A. Marr, ${ }^{\text {a }}$ Sergey Zlatogorsky, ${ }^{a, b}$ Ronan Bellabarba ${ }^{c}$ and \\ Robert P. Toozec
}

A Sc NHC complex readily activates three equivalents of $\mathrm{CO}_{2}$ showing 'Frustrated Lewis Pair' type reactivity with each metalcarbene bond, but whilst $\mathrm{CS}_{2}$ is also activated by the labile carbenes, no metal involvement is observed.

Carbon dioxide $\left(\mathrm{CO}_{2}\right)$ is an inexpensive and abundant natural resource and an attractive $\mathrm{C}_{1}$ building block for the synthesis of more valuable molecules; ${ }^{1,2}$ thus catalytic reactions using $\mathrm{CO}_{2}$ as a feedstock are currently of great interest. ${ }^{3,4}$ Carbon disulfide $\left(\mathrm{CS}_{2}\right)$ is isoelectronic with $\mathrm{CO}_{2}$ and has a more electrophilic carbon centre due to the weaker $\pi$-donor ability of the softer $\mathrm{S}$, and is often studied as a comparator for $\mathrm{CO}_{2}$.

Neutral N-heterocyclic carbenes (NHCs) are highly nucleophilic and are known to react with both $\mathrm{CO}_{2}$ and $\mathrm{CS}_{2}$ to form zwitterionic imidazolium carboxylates $\left(\mathrm{NHC} \cdot \mathrm{CO}_{2}\right)$ and dithiocarboxylates $\left(\mathrm{NHC} \cdot \mathrm{CS}_{2}\right)$ respectively (A in Chart 1$) .{ }^{5}$ Imidazolium carboxylates have been shown to successfully catalyse reactions such as the coupling of epoxides and carbon dioxide to produce cyclic carbamates. ${ }^{6}$ The more Lewis basic nature of

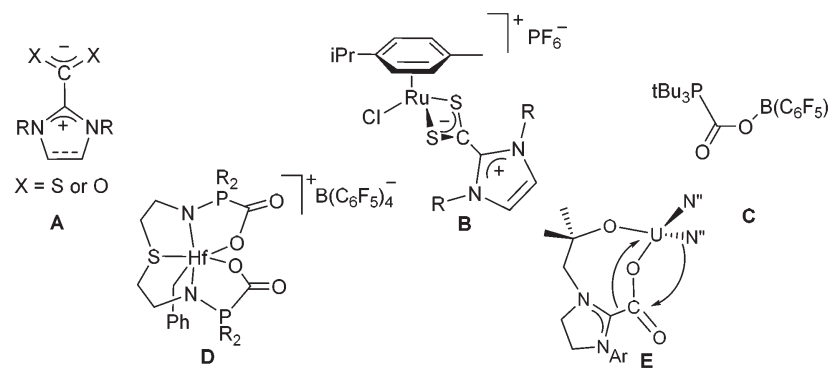

Chart 1

\footnotetext{
${ }^{a}$ EaStCHEM School of Chemistry, University of Edinburgh, The King's Buildings, Edinburgh, EH9 3JJ, UK. E-mail: polly.arnold@ed.ac.uk

${ }^{b}$ School of Forensic and Investigative Sciences, The University of Central Lancashire, Preston, PR1 2HE, UK

${ }^{c}$ Sasol Technology UK, Purdie Building, North Haugh, St Andrews, KY16 9SR, UK $\dagger$ Celebrating 300 years of Chemistry at Edinburgh.

\$Electronic supplementary information (ESI) available: Full experimental and crystallographic data. CCDC 954361-954364. For ESI and crystallographic data in CIF or other electronic format see DOI: 10.1039/c3dt52762j
}

imidazolium dithiocarboxylates has allowed them to be used successfully as catalysts for the cyanosilylation of aldehydes, ${ }^{7}$ and in the Staudinger reaction to prepare $\beta$-lactams. ${ }^{8}$

Delaude demonstrated that the NHC. $\mathrm{CS}_{2}$ can also be used as ligand and coordinates as a $\kappa^{2}, S, S^{\prime}$ chelate to the $\mathrm{Ru}^{\mathrm{II}}$ centre in the first examples of transition-metal complexes with such ligands (B in Chart 1). His experiments also demonstrated the greater stability of the $\mathrm{NHC} \cdot \mathrm{CS}_{2}$ than $\mathrm{NHC} \cdot \mathrm{CO}_{2}$ betaines towards $\mathrm{CE}_{2}$ loss. ${ }^{9}$

Frustrated Lewis pair (FLPs) systems are combinations of Lewis acids and Lewis bases that are prevented from reacting together by steric congestion. These have been used to activate $\mathrm{CO}_{2}$, for example, Stephan used $\mathrm{B}\left(\mathrm{C}_{6} \mathrm{~F}_{5}\right)_{3}$ and $\mathrm{P} \mathrm{Bu}_{3}$ to trap $\mathrm{CO}_{2}$ (C in Chart 1). ${ }^{10}$ Such activation of $\mathrm{CO}_{2}$ using FLPs has allowed subsequent reduction to methanol and methane. ${ }^{11,12}$ There are few, but an increasing number, of transition metal FLP type systems which can activate $\mathrm{CO}_{2}$ in the same way as main group FLPs. Wass used $\left[\mathrm{Cp}_{2} \mathrm{Zr}\left(\mathrm{OC}_{6} \mathrm{H}_{4} \mathrm{P}^{t} \mathrm{Bu}_{2}\right)\right]\left[\mathrm{B}\left(\mathrm{C}_{6} \mathrm{~F}_{5}\right)_{4}\right]$ to trap $\mathrm{CO}_{2}{ }^{13}$ and Stephan used a cationic hafnium complex

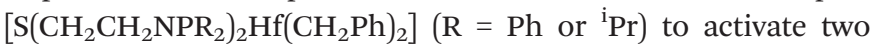
equivalents of $\mathrm{CO}_{2}$ in a FLP type manner (D in Chart 1$) .{ }^{14}$ We and others have studied the NHC as the Lewis base centre in metal-FLP chemistry using complexes in which the M-NHC bond is very weak. ${ }^{15-19}$ For example, $\mathrm{U}\left(\mathrm{L}^{\mathrm{R}}\right) \mathrm{N}_{2}{ }_{2} \quad(\mathrm{~L}=$ $\mathrm{OCMe}_{2} \mathrm{CH}_{2}\left(1-\mathrm{C}\left\{\mathrm{NCH}_{2} \mathrm{CH}_{2} \mathrm{NR}\right\}\right), \mathrm{R}=2,6{ }^{\mathrm{i}}{ }^{\mathrm{Pr}}-\mathrm{C}_{6} \mathrm{H}_{3}$ or $2,4,6-\mathrm{Me}-$ $\left.\mathrm{C}_{6} \mathrm{H}_{2}, \mathrm{~N}^{\prime \prime}=\mathrm{N}\left(\mathrm{SiMe}_{3}\right)_{2}\right)$ reacts with $\mathrm{CO}_{2}$ to form $\left[\mathrm{U}\left(\mathrm{L}^{\mathrm{R}}\right) \mathrm{N}^{\prime \prime}-\right.$ $\left.\left(\mathrm{OSiMe}_{3}\right)\left(\mathrm{O}=\mathrm{C}=\mathrm{NSiMe}_{3}\right)\right]_{n},{ }^{20}$ presumed to proceed via $\mathbf{E}$ in Chart 1. Herein, we report the synthesis of a homoleptic scandium-alkoxy-NHC complex and its reactivity with both $\mathrm{CO}_{2}$ and $\mathrm{CS}_{2}$.

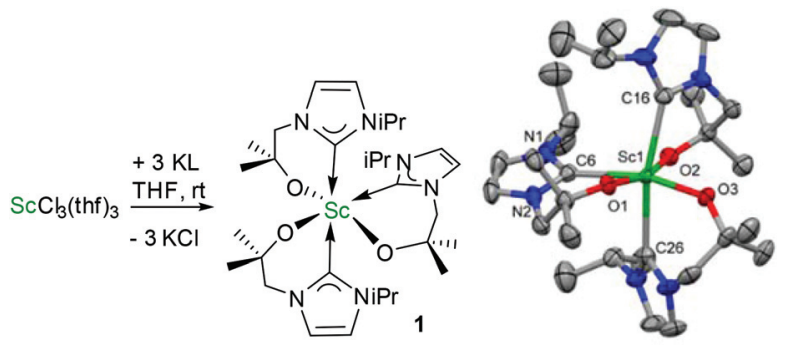


Treatment of $\mathrm{ScCl}_{3}$ (thf $)_{3}$ with three equivalents of $\mathrm{KL}(\mathrm{L}=$ $\left.\left[\mathrm{OCMe}_{2} \mathrm{CH}_{2}\left(1-\mathrm{C}\left\{\mathrm{NCHCHN}^{\mathrm{i}} \mathrm{Pr}\right\}\right)\right]\right)$ affords $\mathrm{Sc}(\mathrm{L})_{3} \mathbf{1}$ in a $67 \%$ yield, eqn (1). The ${ }^{1} \mathrm{H}$ NMR spectrum of $\mathbf{1}$ at room temperature shows one set of broad ligand resonances which would indicate either $C_{3}$ symmetry in solution or that a fluxional process between free and bound carbenes is occurring on the NMR timescale. A variable temperature ${ }^{1} \mathrm{H}$ NMR study $\left(20{ }^{\circ} \mathrm{C}\right.$ to $-70{ }^{\circ} \mathrm{C}$ ) of a $\mathrm{d}_{8}$-toluene solution of 1 was undertaken (see $\mathrm{ESI} \dagger$ for spectra). Upon cooling, decoalescence features begin to be observed at $263 \mathrm{~K}$, presumably the point at which the labile carbene dissociates readily from the metal. At $233 \mathrm{~K}$ two sets of broadened ligand resonances can be made out, with the isopropyl septet the most obvious feature (a septet which resonates at $5.85 \mathrm{ppm}$ at $298 \mathrm{~K}$, split to 6.73 and $5.49 \mathrm{ppm}$ at $233 \mathrm{~K}$ in a $1: 2$ ratio). At lower temperatures still, further splitting of the ligand resonances is observed. Again, observing the isopropyl $\mathrm{CH}$, the lower frequency resonance splits into two resonances (split from 5.49 to 5.46 and $5.50 \mathrm{ppm}$ at $203 \mathrm{~K}$ ). At $203 \mathrm{~K}$ three sets of ligand resonances are clearly present showing all three ligands to be in inequivalent environments to one another, indicating meridionally-aligned ligands. It can be observed from the spectrum at this temperature that all methyl groups and $\mathrm{CH}_{2}$ protons in the molecule are diastereotopic.

X-ray quality single crystals of $\mathbf{1}$ were grown by slow diffusion of hexane into a concentrated benzene solution at $298 \mathrm{~K}$ over five days. The molecular structure of the $\Lambda$-mer enantiomer of $\mathbf{1}$ is shown alongside eqn (1) (the asymmetric unit contains both $\Delta$-mer and $\Lambda$-mer enantiomers). The molecule is isostructural with $\operatorname{Ti}(\mathrm{L})_{3}$ and $\mathrm{Y}(\mathrm{L})_{3}$, previously reported by our group. ${ }^{21,22}$ The Sc centre lies in a pseudo-octahedral environment, coordinated by three bidentate ligands in a merconformation. The mean $\mathrm{Sc}-\mathrm{C}_{\text {carbene }}$ bond distance is $2.436 \AA$, range 2.411 (3) $\AA$ to 2.495(3) $\AA$. The bond between the metal and the NHC trans to the alkoxide group is notably longer than the other two $\mathrm{Sc}-\mathrm{C}_{\text {carbene }}$ bond distances $(2.452(3) c f$. 2.411(3) and 2.402(3) $\AA$ in the $\Delta$-mer isomer). Conversely, the distance between the scandium centre and alkoxide trans to the NHC is the shortest of the three Sc-O bonds in both molecules (1.989(2) cf. 2.036(2) and 2.046(2) ̊). The structure exhibits similar long trans $\mathrm{NHC}-\mathrm{M}$ distances to those in $\mathrm{Y}(\mathrm{L})_{3}$ and $\mathrm{Ti}(\mathrm{L})_{3} \cdot{ }^{21,22}$ The mean $\mathrm{Sc}-\mathrm{C}_{\text {carbene, }}$, bond length $(2.422 \AA)$ in 1 is comparable with other Sc-NHC complexes. For example, the distances in $\left[\mathrm{Sc}\left(\mathrm{L}^{\mathrm{D}}\right)_{2}\left(\mathrm{CH}_{2} \mathrm{SiMe}_{3}\right)\right]\left(\mathrm{L}^{\mathrm{D}}=\left(\left\{\mathrm{C}\left(\mathrm{NDippCH}_{2} \mathrm{CH}_{2} \mathrm{~N}\right)\right\}-\right.\right.$ $\left.\left.\mathrm{CH}_{2} \mathrm{CMe}_{2} \mathrm{O}\right)\right)$ and $\left[\mathrm{Sc}\left(\mathrm{Ind}\left(\mathrm{CH}_{2} \mathrm{CH}_{2}(1-\mathrm{C}\{\mathrm{NCHCHNMes}\})\right)\right)-\right.$ $\left.\left(\mathrm{CH}_{2} \mathrm{SiMe}_{3}\right)_{2}\right]$ (Ind $=$ indole) are 2.442 (mean) and 2.350(3) $\AA$ respectively. ${ }^{18,23}$ However, the $\mathrm{M}-\mathrm{C}$ bond of 2.495(3) $\AA$ for the carbene trans to the alkoxide in $\mathbf{1}$ is the longest Sc-NHC distance yet reported, suggesting lability. ${ }^{18,24,25}$

To investigate the potential for the Sc-NHC combination to engage in FLP-type behaviour, reactions of 1 with $\mathrm{CO}_{2}$ and $\mathrm{CS}_{2}$ were investigated. A solution of $\mathbf{1}$ in benzene was exposed to an atmosphere of $\mathrm{CO}_{2}$ upon which a colourless precipitate, 2, immediately formed, Scheme 1 . The isolated precipitate is insoluble in solvents with which it does not react, and assigned as the product of insertion of 3 equivalents of $\mathrm{CO}_{2}$

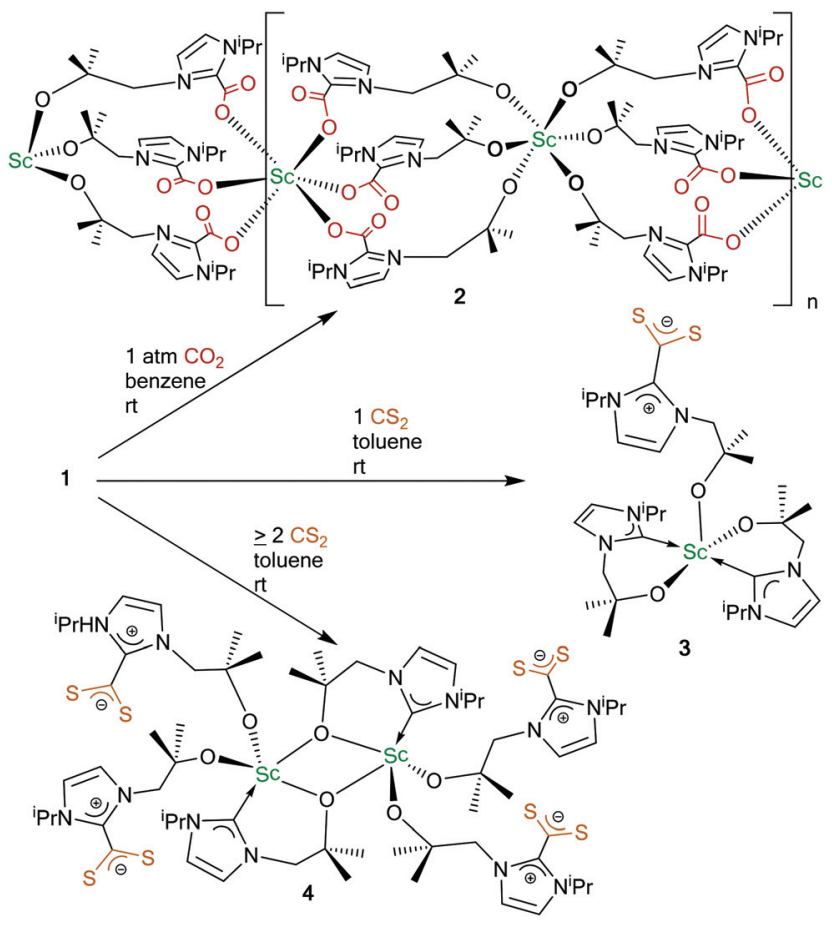

Scheme 1 Reactions of 1 with $\mathrm{CO}_{2}$ and $\mathrm{CS}_{2}$.

into the Sc-C bonds, $\mathrm{Sc}\left(\mathrm{OCMe}_{2} \mathrm{CH}_{2}\left(1-\mathrm{O}_{2} \mathrm{CC}\left\{\mathrm{NCHCHN}^{\mathrm{i}} \mathrm{Pr}\right\}\right)\right)_{3} 2$ (abbreviated as $\mathrm{Sc}\left(\mathrm{L}^{\mathrm{CO}_{2}}\right)_{3}$ ) from elemental analysis, FTIR, and solid state NMR spectroscopies. Infrared spectroscopy (nujol mull) shows one set of distinct carbonyl stretching frequencies to be present, indicating high symmetry. The band at $1672 \mathrm{~cm}^{-1}$ is assigned as the $\mathrm{COO}^{-}$asymmetric stretch for the imidazolium carboxylate, which typically range from $\mathrm{ca} .1630$ to $1690 \mathrm{~cm}^{-1}$ depending on the $N$-substituents. ${ }^{26,27}$

The ${ }^{13} \mathrm{C}$ MAS NMR spectrum of 2 shows a single set of resonances assignable to the ligand resonances. Most notably, two resonances at 156.1 and $145.0 \mathrm{ppm}$ are assigned to the carbons of the NHC-coordinated $\mathrm{CO}_{2}$ and the azolium $\mathrm{C}_{2}$ respectively. ${ }^{27}$ The resonances are slightly broader than expected, which combined with the insolubility, suggest a polymeric structure, formed through ligand bridging. Finally, the observation of two resonances in the ${ }^{45}$ Sc MAS NMR spectrum of 2, at $128 \mathrm{ppm}$ and $45 \mathrm{ppm}$, has led us to propose the polymeric structure of 2 as shown in Scheme 1. The two chemical shifts are both indicative of a $\left[\mathrm{ScO}_{6}\right]$, six-coordinate Sc centre ligated exclusively by oxygen atoms, with the broader resonance at $45 \mathrm{ppm}(\mathrm{fwhm}=12 \mathrm{kHz})$ arising from a less symmetric environment at Sc. ${ }^{28,29}$

For comparison, reactions with one, two, and an excess of equivalents of $\mathrm{CS}_{2}$ were studied. Treatment of $\mathbf{1}$ with one equivalent of $\mathrm{CS}_{2}$ in toluene affords the microcrystalline red solid $\left[\mathrm{Sc}\left(\mathrm{OCMe}_{2} \mathrm{CH}_{2}\left(1-\mathrm{S}_{2} \mathrm{CC}\left\{\mathrm{NCHCHN}^{\mathrm{i}} \mathrm{Pr}\right\}\right)\right)(\mathrm{L})_{2}\right], \quad 3 \quad\left(\mathrm{Sc}\left(\mathrm{L}^{\mathrm{CS}_{2}}\right)(\mathrm{L})_{2}\right)$, which was shown by a single crystal X-ray study to contain a single dithiocarboxylated imidazolium group, coordinated to Sc through the alkoxide. The ${ }^{1} \mathrm{H}$ NMR spectrum of 3 shows two sets of ligand resonances in a $2: 1$ ratio and the ${ }^{13} \mathrm{C}$ NMR spectrum is in agreement, with the resonance at $226.7 \mathrm{ppm}$ 
attributed to the dithiocarboxylate group and a resonance at 150.6 ppm attributed to the $\mathrm{C}_{2}$ imidazolium carbon through which $\mathrm{CS}_{2}$ is bound. In previously reported imidazolium-2dithiocarboxylates the $\mathrm{CS}_{2}$ carbon resonance is usually observed in the range 220-226 ppm, and the $\mathrm{C}_{2}$ in the unsaturated imidazolium ring around $149 \mathrm{ppm} .{ }^{30,31}$ In a separate reaction, we also isolated the $\mathrm{CS}_{2}$ adduct of the proligand, $\mathrm{HL} \cdot \mathrm{CS}_{2}$; full characterisation including a single crystal X-ray structure, is in the ESI. $\dagger$

Treatment of 1 with two equivalents of $\mathrm{CS}_{2}$ in toluene leads to immediate formation of $\mathbf{3}$, followed by the slow formation of $\left[\mathrm{Sc}\left(\mathrm{OCMe}_{2} \mathrm{CH}_{2}\left(1-\mathrm{S}_{2} \mathrm{CC}\left\{\mathrm{NCHCHN}^{\mathrm{i}} \mathrm{Pr}\right\}\right)\right)_{2}(\mathrm{~L})\right], 4$ abbreviated as $\mathrm{Sc}\left(\mathrm{L}^{\mathrm{CS}_{2}}\right)_{2}(\mathrm{~L})$, as a red oil, evidenced by monitoring the reaction by ${ }^{1} \mathrm{H}$ NMR. The addition of further equivalents of $\mathrm{CS}_{2}$ does not lead to the formation of $\mathrm{Sc}\left(\mathrm{L}^{\mathrm{CS}_{2}}\right)_{3}$ but instead accelerates the rate at which $\mathbf{4}$ is formed. Notably, in a reaction where $\mathrm{CS}_{2}$ was used as both solvent and reagent, diffraction quality crystals of $\mathbf{4}$ were grown from the reaction mixture.§ Bright red $\mathrm{X}$-ray quality single crystals of 3 were grown by slow diffusion of hexane into a concentrated benzene solution of 3 over a period of one week.

The molecular structures of 3 and $\mathbf{4}$ are shown in Fig. 1. In the solid state 3 is monomeric with five coordinate-scandium positioned in a distorted square planar pyramidal environment. Whilst it can be ascertained that the two bound alkoxy tethered carbenes form the square base whilst the fifth coordination site is occupied by the alkoxy-bound pendant imidazolium-dithiocarboxylate group, which points away from the metal centre, the data are not of high quality. There are two independent molecules of $\mathbf{3}$ present in the asymmetric unit which are enantiomers.

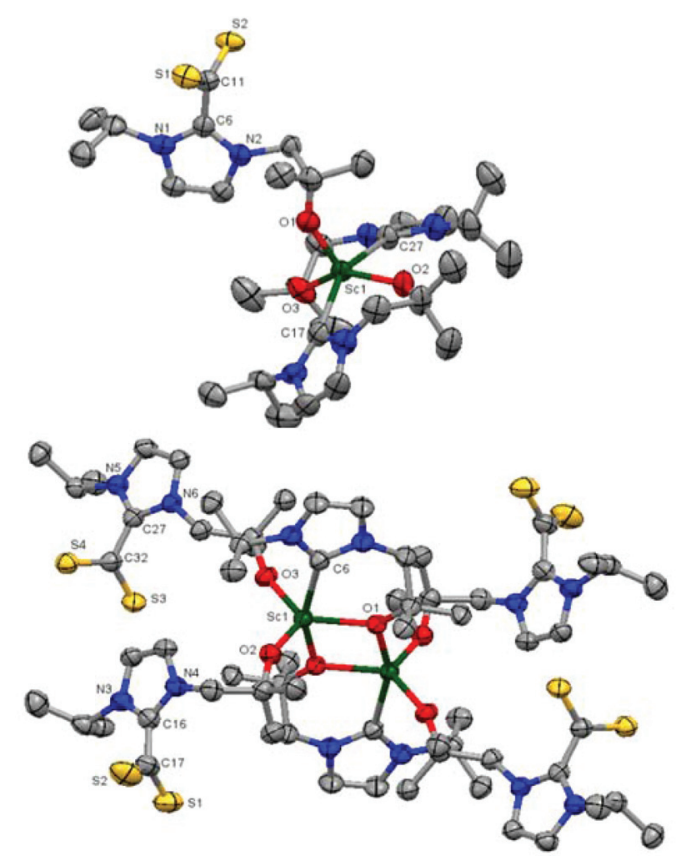

Fig. 1 Displacement ellipsoid plot of the molecular structures of 3 and 4 (50\% probability ellipsoids). $\mathrm{H}$ atoms omitted for clarity.
Complex 4 is dimeric in the solid state with an alkoxy bridged $\mathrm{Sc}_{2} \mathrm{O}_{2}$ core. Each metal centre is five-coordinate, distorted trigonal bipyramidal geometry, and the $\mathrm{CS}_{2}$ plane is always orthogonal to the imidazolium plane. Salient bond distances are similar in compounds 3 and $\mathbf{4}$ (but see caveat above). The mean $\mathrm{Sc}-\mathrm{C}_{\text {carbene }}$ bond distance in 3 is $2.411 \AA$ and in 4 2.391(4) $\AA$, the latter is significantly shorter than in 1 (mean distance $2.436 \AA$ ). The mean $\mathrm{C}-\mathrm{C}$ bond distance between the $\mathrm{N}_{2} \mathrm{C}^{+}$unit and the $\mathrm{CS}_{2}{ }^{-}$unit in 4 is $1.481 \AA .{ }^{5,31,32}$ Most surprising in both $\mathbf{3}$ and $\mathbf{4}$ is the absence of interaction between the scandium centre and the $\mathrm{CS}_{2}$ group, despite its formal negative charge. ${ }^{9}$

To conclude, $\mathrm{Sc}(\mathrm{L})_{3}$ readily incorporates three equivalents of $\mathrm{CO}_{2}$ showing 'Frustrated Lewis Pair' type reactivity, but it has not been possible to incorporate fewer equivalents. $\mathrm{CS}_{2}$ is coordinated through the same general $\mathbf{M}$-NHC insertion process, but the $\mathrm{CS}_{2}$ part of the zwitterion formed does not compete with the NHC group for the Sc centre. Despite the proven lability of the NHC group, only up to two can be displaced by $\mathrm{CS}_{2}$ incorporation. Work is in progress to identify further reactions that allow these $\mathrm{CE}_{2}$ groups to be transferred into other organic substrates.

We are grateful to Prof. S.E. Ashbrook and Mr D. Dawson for collection and interpretation of the solid state NMR spectroscopic data.

\section{Notes and references}

$\S$ Crystals of $\mathbf{4}$ were also grown by adding a few drops of thf, then three equivalents of $\mathrm{CS}_{2}$ to a toluene solution of $\mathbf{1}$ at room temperature.

1 C. Finn, S. Schnittger, L. J. Yellowlees and J. B. Love, Chem. Commun., 2012, 48, 1392.

2 D. H. Gibson, Chem. Rev., 1996, 96, 2063.

3 L. Zhang and Z. Hou, Chem. Sci., 2013, 4, 3395.

4 O. Jacquet, X. Frogneux, C. Das Neves Gomes and T. Cantat, Chem. Sci., 2013, 4, 2127.

5 L. Delaude, Eur. J. Inorg. Chem., 2009, 2009, 1681.

6 H. Zhou, W. Z. Zhang, C. H. Liu, J. P. Qu and X. B. Lu, J. Org. Chem., 2008, 73, 8039.

7 A. Blanrue and R. Wilhelm, Synlett, 2004, 2621.

8 O. Sereda, A. Blanrue and R. Wilhelm, Chem. Commun., 2009, 1040 .

9 L. Delaude, X. Sauvage, A. Demonceau and J. Wouters, Organometallics, 2009, 28, 4056.

10 C. M. Mömming, E. Otten, G. Kehr, R. Fröhlich, S. Grimme, D. W. Stephan and G. Erker, Angew. Chem., Int. Ed., 2009, 48, 6643.

11 G. Menard and D. W. Stephan, J. Am. Chem. Soc., 2010, 132, 1796.

12 A. E. Ashley, A. L. Thompson and D. O'Hare, Angew. Chem., Int. Ed., 2009, 48, 9839.

13 A. M. Chapman, M. F. Haddow and D. F. Wass, J. Am. Chem. Soc., 2011, 133, 18463. 
14 M. J. Sgro and D. W. Stephan, Chem. Commun., 2013, 49, 2610.

15 E. L. Kolychev, T. Bannenberg, M. Freytag, C. G. Daniliuc, P. G. Jones and M. Tamm, Chem.-Eur. J., 2012, 18, 16938.

16 D. Palomas, S. Holle, B. Ines, H. Bruns, R. Goddard and M. Alcarazo, Dalton Trans., 2012, 41, 9073.

17 Y. T. Zhang, G. M. Miyake, M. G. John, L. Falivene, L. Caporaso, L. Cavallo and E. Y. X. Chen, Dalton Trans., 2012, 41, 9119.

18 P. L. Arnold, Z. R. Turner, R. Bellabarba and R. P. Tooze, J. Am. Chem. Soc., 2011, 133, 11744.

19 I. J. Casely, S. T. Liddle, A. J. Blake, C. Wilson and P. L. Arnold, Chem. Commun., 2007, 5037.

20 P. L. Arnold, Z. R. Turner, A. I. Germeroth, I. J. Casely, G. S. Nichol, R. Bellabarba and R. P. Tooze, Dalton Trans., 2013, 42, 1333.

21 N. A. Jones, S. T. Liddle, C. Wilson and P. L. Arnold, Organometallics, 2007, 26, 755.

22 P. L. Arnold, S. Zlatogorsky, N. A. Jones, C. D. Carmichael, S. T. Liddle, A. J. Blake and C. Wilson, Inorg. Chem., 2008, 47, 9042 .
23 B. Wang, D. Wang, D. Cui, W. Gao, T. Tang, X. Chen and X. Jing, Organometallics, 2007, 26, 3167.

24 B. Wang, D. Cui and K. Lv, Macromolecules, 2008, 41, 1983. 25 A. Wacker, C. G. Yan, G. Kaltenpoth, A. Ginsberg, A. M. Arif, R. D. Ernst, H. Pritzkow and W. Siebert, J. Organomet. Chem., 2002, 641, 195.

26 B. R. Van Ausdall, J. L. Glass, K. M. Wiggins, A. M. Aarif and J. Louie, J. Org. Chem., 2009, 74, 7935.

27 E. Brule, V. Guerineau, P. Vermaut, F. Prima, J. Balogh, L. Maron, A. M. Z. Slawin, S. P. Nolan and C. M. Thomas, Polym. Chem., 2013, 4, 2414.

28 M. D. Alba, P. Chain, P. Florian and D. Massiot, J. Phys. Chem. C, 2010, 114, 12125.

29 A. J. Rossini and R. W. Schurko, J. Am. Chem. Soc., 2006, 128, 10391.

30 L. Delaude, A. Demonceau and J. Wouters, Eur. J. Inorg. Chem., 2009, 1882.

31 U. Siemeling, H. Memczak, C. Bruhn, F. Vogel, F. Trager, J. E. Baio and T. Weidner, Dalton Trans., 2012, 41, 2986.

32 H. A. Duong, T. N. Tekavec, A. M. Arif and J. Louie, Chem. Commun., 2004, 112. 